TITLE:

\title{
Surface-wave analysis for identifying unfrozen zones in subglacial sediments
}

\section{$\operatorname{AUTHOR}(\mathrm{S}):$}

Tsuji, Takeshi; Johansen, Tor Arne; Bent Ole Ruud; Ikeda, Tatsunori; Matsuoka, Toshifumi

\section{CITATION:}

Tsuji, Takeshi .... [et al]. Surface-wave analysis for identifying unfrozen zones in subglacial sediments. GEOPHYSICS 2012, 77(3): EN17-EN27

\section{ISSUE DATE:}

2012-04

URL:

http://hdl.handle.net/2433/163454

RIGHT:

(C)2012 Society of Exploration Geophysicists 


\title{
Surface-wave analysis for identifying unfrozen zones in subglacial sediments
}

\author{
Takeshi Tsuji ${ }^{1}$, Tor Arne Johansen ${ }^{2}$, Bent Ole Ruud ${ }^{3}$, Tatsunori Ikeda ${ }^{4}$, and \\ Toshifumi Matsuoka ${ }^{1}$
}

\begin{abstract}
To reveal the extent of freezing in subglacial sediments, we estimated S-wave velocity along a glacier using surface-wave analysis. Because the $\mathrm{S}$-wave velocity varies significantly with the degree of freezing of the pore fluid in the sediments, this information is useful for identifying unfrozen zones within subglacial sediments, which again is important for glacier dynamics. We used active-source multichannel seismic data originally acquired for reflection analysis along a glacier at Spitsbergen in the Norwegian Arctic and proposed an effective approach of multichannel analysis of surface waves (MASW) in a glacier environment. Common-midpoint crosscorrelation gathers were used for the MASW to improve lateral resolution because the glacier bed has a rough topology. We used multimode analysis with a genetic algorithm inversion to
\end{abstract}

estimate the S-wave velocity due to the potential existence of a low-velocity layer beneath the glacier ice and the observation of higher modes in the dispersion curves. In the inversion, we included information of ice thickness derived from highresolution ground-penetrating radar data because a simulation study demonstrated that the ice thickness was necessary to estimate accurate S-wave velocity distribution of deep subglacial sediment. The estimated S-wave velocity distribution along the seismic line indicated that low velocities occurred below the glacier, especially beneath thick ice $(\sim 1300 \mathrm{~m} / \mathrm{s}$ for ice thicknesses larger than $50 \mathrm{~m})$. Because this velocity was much lower than the velocity in pure ice $(\sim 1800 \mathrm{~m} / \mathrm{s})$, the pore fluid was partially melted at the ice-sediment interface. At the shallower subglacial sediments (ice thickness less than $50 \mathrm{~m}$ ), the S-wave velocity was similar to that of the pure ice, suggesting that shallow subglacial sediments are more frozen than sediments beneath thick ice.

\section{INTRODUCTION}

Because the presence of liquid water lubricates the glacier icesubglacial sediment interfaces, meltwater drainage influences the flow rate of glaciers. Therefore, estimation of the spatial distribution of unfrozen zones within subglacial sediments, as well as subglacial meltwater channels, is crucial for the study of glacier dynamics (e.g., glacier cyclicity). To estimate the degree of freezing in such sediments, seismic surveys would provide useful information because seismic velocities in porous rocks vary significantly with the degree of pore-fluid freezing (Zimmermann and King, 1986; Jacoby et al., 1996; Johansen et al., 2003). A small amount of frozen water in the voids of a porous sediment rock can lead to large
S-wave velocity increases (Johansen et al., 2003). Hence, the Swave velocity distributions derived from surface-wave analysis could provide useful information to reveal the degree of freezing of subglacial sediments. For the seismic line used in this study, high-resolution ground-penetrating radar (GPR) data are available (Johansen et al., 2011). Previous studies have demonstrated that GPR is an effective tool for glacier characterization (e.g., Woodward et al., 2003). The GPR data, acquired with a constant offset, do not provide any velocity information. The observed reflection times from the base of the glacier are converted to depth using a constant velocity of $0.17 \mathrm{~m} / \mathrm{ns}$ in the ice. The glacier geometry derived from the GPR data is integrated in the surface-wave analysis

\footnotetext{
Manuscript received by the Editor 21 June 2011; revised manuscript received 11 January 2012; published online 3 April 2012.

${ }^{1}$ Formerly Kyoto University, Graduate School of Engineering, Kyoto, Japan; presently Kyushu University, International Institute for Carbon-Neutral Energy Research, Fukuoka, Japan. E-mail: tsuji@earth.kumst.kyoto-u.ac.jp.

${ }^{2}$ University of Bergen, Department of Earth Science, and NORSAR Bergen, Bergen, Norway. E-mail: torarne.johansen@geo.uib.no.

${ }^{3}$ University of Bergen, Department of Earth Science, Bergen, Norway. E-mail: bent.ruud@geo.uib.no.

${ }^{4}$ Kyoto University, Graduate School of Engineering, Kyoto, Japan. E-mail: matsuoka@earth.kumst.kyoto-u.ac.jp.

(C) 2012 Society of Exploration Geophysicists. All rights reserved.
} 
to see if we can improve the resolution of the seismic velocities in the subglacial sediments.

Rayleigh waves, generated by the interaction of P- and S-waves at the surface of the earth, are polarized elliptically in the vertical plane containing the direction of propagation. If the elastic constants change with depth, the velocity of Rayleigh waves varies with frequency. The dispersion of the phase velocity of a Rayleigh wave can be used to obtain the S-wave velocity at depth scales ranging from the upper mantle (e.g., Yao et al., 2008) to the near-surface zone, where surface-wave analysis has applications in geotechnical engineering (e.g., Hayashi and Suzuki, 2004; Lin et al., 2004). For geotechnical purposes, spectral analysis of surface waves (SASW) is used to determine 1D S-wave velocity structures to depths of $100 \mathrm{~m}$ (Nazarian et al., 1983). Most SASW methods calculate phase differences between two receivers using a crosscorrelation of their recorded waveforms and determine the phase velocities from differently spaced crosscorrelations (receiver pair) separately.

To reduce incoherent noise in SASW, several authors have determined the dispersion curve from multichannel data. McMechan and Yedlin (1981) propose a method that can transform timedistance domain data to slowness-frequency domain from multichannel shot gathers using the $\tau$ - $p$ transform. Park et al. (1998, 1999 a , 1999b) also propose an integral transformation to phasevelocity frequency-domain data called multichannel analysis of surface-waves (MASW) method. MASW can calculate a higherresolution dispersion image compared to McMechan and Yedlin's (1981) method (Park et al., 1999a). MASW is more useful than SASW because, by stacking in the frequency-wavenumber $(f-k)$ domain, it can reduce the extent of incoherent noise events which are often encountered in SASW and visually distinguish the fundamental mode of the Rayleigh wave from other modes (i.e., higher modes and body waves) in the dispersion analysis. In this study, we apply MASW to active-source long-offset seismic data acquired on top of a glacier in south-central Spitsbergen in the Norwegian Arctic.

The surface of the glacier bed has a rough topology, although the surface-wave analysis is conventionally assumed to be a horizontally layered structure for S-wave velocity estimation. To improve the lateral resolution of the estimated S-wave velocity structure, we use a common-midpoint crosscorrelation (CMPCC) analysis (Hayashi and Suzuki, 2004). Furthermore, characteristics of the dispersion curve are sensitively related to the seismic properties of the subglacial sediment. Sharp velocity contrasts as well as a lowvelocity layer at the ice-sediment interface generate higher modes in the dispersion curve. Therefore, the multimode analysis could be convenient to use for studying the dynamics of the glacier system.

\section{METHOD}

\section{Common-midpoint crosscorrelation analysis}

To determine accurate velocity structures for deep lithologies, it is necessary to use a long receiver array with large channel number for MASW. However, this decreases the lateral resolution because the conventional MASW method provides an averaged velocity over the total span of the array (Hayashi and Suzuki, 2004). A shorter array provides better lateral resolution in cases where the lithology has a significant lateral velocity variation. A trade-off therefore exists between lateral resolution and investigation depth with respect to the $\mathrm{S}$-wave velocity structure.

To improve the lateral resolution of our long-receiver-array data, we use a crosscorrelation analysis that generates a CMPCC gather (Hayashi and Suzuki, 2004). When we use shot gathers in the surface-wave analysis, the midpoints of the receiver pairs are widely distributed. Therefore, the estimated S-wave velocity represents an average value over a wide area. However, because the waveforms in the CMPCC gather have the same common midpoint (CMP), it increases lateral resolution compared to shot gathers, as in reflection seismology. Ice thickness can change abruptly in the horizontal direction due to U-shaped glacial valley, so the application of the CMPCC approach to study subglacial sediment is effective for resolving its $\mathrm{S}$-wave velocity.

Data acquisition for the CMPCC method is similar to the acquisition usually performed for a 2D seismic reflection survey. Every pair of traces in a shot gather is crosscorrelated before being sorted into CMP gathers. At each CMP point, the equally spaced crosscorrelated traces are stacked in the time domain. Differently spaced crosscorrelations are ordered with respect to their spacing in each CMP. The resultant CMPCC gathers contain only the characteristics of phase differences at each CMP location (Hayashi and Suzuki, 2004).

\section{Multichannel analysis of surface waves}

Dispersion curves can be calculated from the CMPCC gathers using the MASW method proposed by Park et al., (1998, 1999a, 1999b). First, each trace in the CMPCC gathers is transformed to the frequency domain via the fast Fourier transform. The CMPCC gathers in the frequency domain $F(x, \omega)$ are then integrated over receiver space using a phase shift calculated for a fixed apparent velocity (phase velocity $c$ ). This integration is repeated for a range of apparent velocities as follows:

$$
F(c, \omega)=\int_{-\infty}^{+\infty} \frac{F(x, \omega)}{|F(x, \omega)|} e^{i \omega x / c} d x,
$$

where $x$ and $\omega$ denote distance and angular frequency, respectively. By plotting the absolute value of equation 1 on a phase velocity versus frequency diagram, the dispersion image is obtained. Finally, phase-velocity variations with frequency are determined by tracing the peak amplitude of the dispersion image.

Theoretical dispersion curves including higher modes are calculated from $\mathrm{P}$ - and $\mathrm{S}$-wave velocities and density structures using the compound matrix method (Saito and Kabasawa, 1993). Several methods have been proposed to calculate dispersion curves and to avoid numerical instabilities for the high frequencies in phasevelocities computations (e.g., Watson, 1970; Schwab and Knopoff, 1972; Kennett and Kerry, 1979). The method of Saito and Kabasawa (1993) used in our study is essentially equivalent to Watson's (1970) method, although the layered matrix is modified to avoid the use of imaginary numbers.

The embedded low-velocity layer often makes higher modes of surface waves predominant (e.g., Gucunski and Woods, 1992; Tokimatsu et al., 1992), so multimode analysis of surface waves is important in this study due to the existence of a low-velocity layer beneath the ice. In the multimode analysis, we use the theoretical amplitude response of each mode derived by the compound matrix method in addition to phase velocity. The misidentification 
of observed modes causes significant error in inverted velocity models (e.g., Zhang and Chan, 2003; O’Neill and Matsuoka, 2005). Therefore, we employ the multimode inversion without mode identification based on Lu and Zhang (2006), who demonstrate that mode jumping of the observed phase velocity curve is consistent with that of surface displacement distribution for each mode (i.e., amplitude response). In this study, therefore, the amplitude response (Harkrider, 1964, 1970) is used for the identification of the dominant mode; we fit the theoretical phase velocities of the mode with maximum amplitude response to the observed phase velocities in the inversion. The amplitude response can be calculated theoretically for an assumed model by forward calculation, so we do not need to read the mode of observed phase velocities.

By fitting the theoretical dispersion curve to the observed dispersion curve, including higher modes, we can estimate the S-wave velocity at the CMPCC point. Because the effects of S-wave velocity on the phase velocity of Rayleigh waves are dominant over those of P-wave velocity and density (Xia et al., 1999), we only estimate $S$-wave velocity in the inversion; the empirical relationship between P-wave velocity and S-wave velocity (Kitsunezaki et al., 1990) and the relationship between S-wave velocity and density (Ludwig et al., 1970) are used in the calculation of P-wave velocity and density. Here, we use a genetic algorithm (GA) inversion (Yamanaka and Ishida, 1996) because GA avoids all assumptions of linearity between the observables and the unknowns and therefore is not dependent on the reference (initial) velocity model (e.g., Socco et al., 2010). For the inversion of the dispersion curve, the S-wave velocity and thickness of each layer are inferred.

\section{Simulation study}

To evaluate the performance of the multimode analysis and to determine the inversion parameters for studying the sediment below the glacier, we conduct a simulation study (Figure 1). Since the unfrozen zones at the ice-sediment interface should have lower S-wave velocities than pure ice (e.g., Johansen et al., 2003), we use low-velocity layer models (Figure 1a) in the simulation. The shallowest layer of the model is pure ice, with constant seismic velocities and density $\left(V_{\mathrm{P}}=3466 \mathrm{~m} / \mathrm{s}, V_{\mathrm{S}}=1839 \mathrm{~m} / \mathrm{s}\right.$; Kim et al., 2010). To calculate synthetic waveforms (Figure $1 b$ ) from the simulation models, we use the discrete wavenumber integral (DWI) method (Bouchon and Aki, 1977). Subsequent to the application of MASW, the dispersion curves (Figure 1c) are calculated from synthetic waveforms. The low-velocity-layer models explain well the characteristics of the dispersion curves of field data, as described later.

In this simulation study, we change the thickness of the glacier ice (i.e., depth of the unfrozen sediment layer) and characterize the dispersion curves (Figure 1). From the dispersion curves, we clearly observe the higher modes induced by the low-velocity layer beneath the glacier ice. The frequency at the transition of dominant mode where the energy of the fundamental mode starts to decay is related to ice thickness because the dispersion curve of the thicker ice model has the transition of dominant mode at lower frequencies (Figure 1). Thus, multimode inversion will improve the velocity estimation of the subglacial sediment.

In this study, we use a seven-layer model for the inversion. The influence of the number of layers on the inverted results is discussed
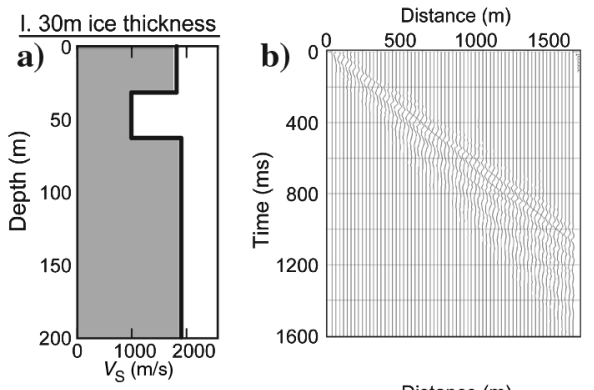

II. $70 \mathrm{~m}$ ice thickness
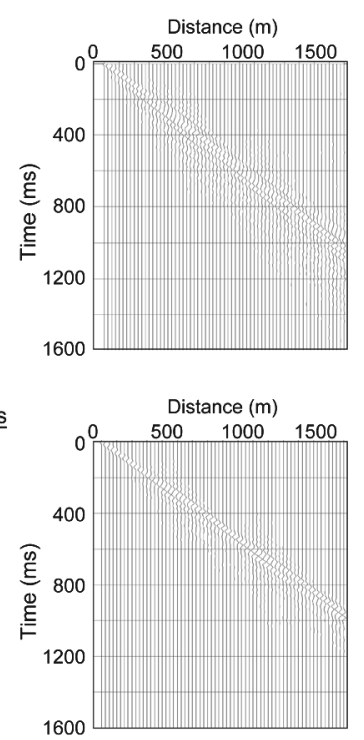

III. $150 \mathrm{~m}$ ice thickness
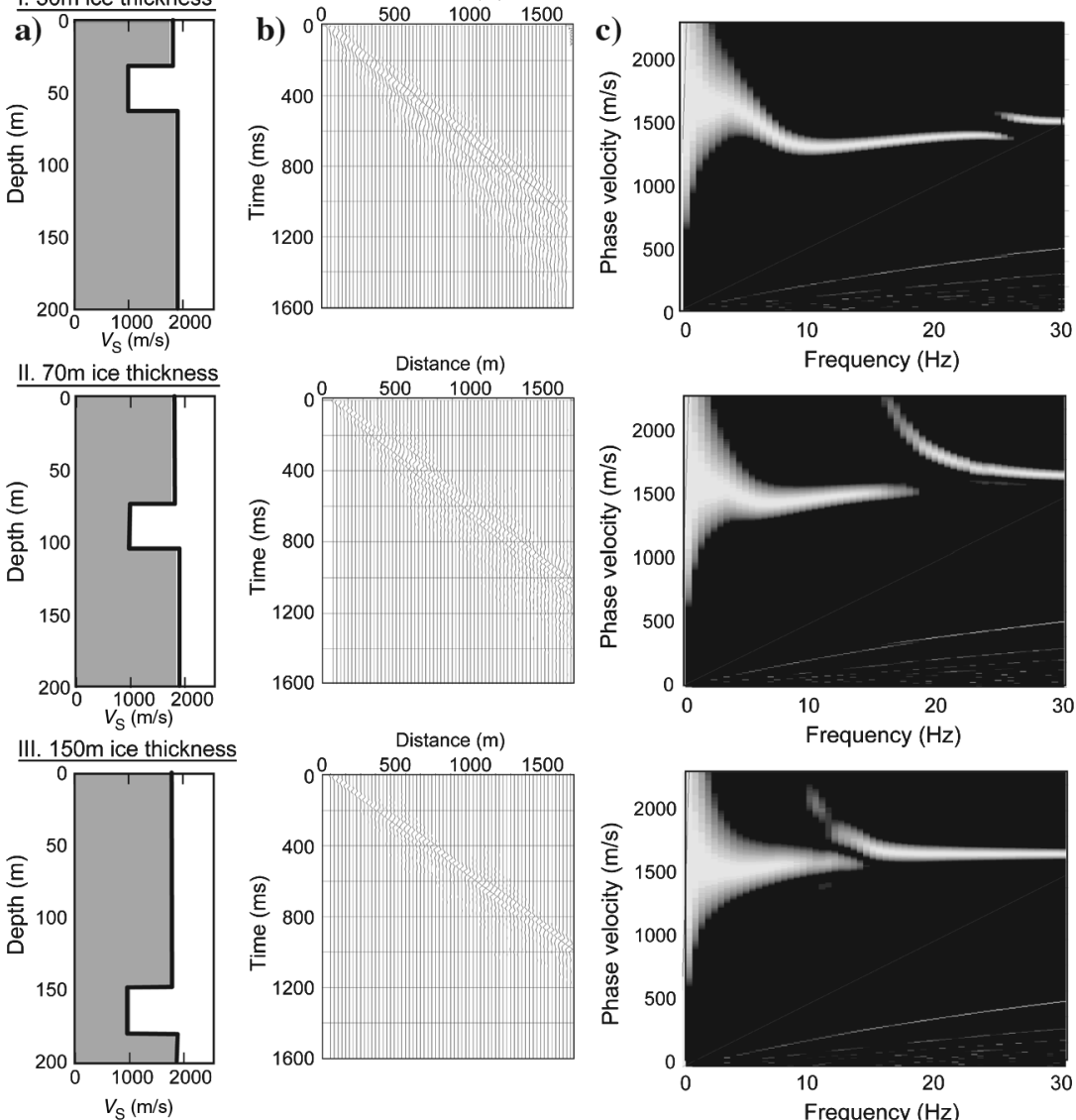

Figure 1. (a) S-wave velocity models with glacier thicknesses of 30,70 , and $150 \mathrm{~m}$. (b) Synthetic wavefield calculated using the DWI method. (c) Dispersion images calculated from the synthetic waveforms. 
in Appendix A. To evaluate its convergence, we calculate the rms error for each generation. As a result, we choose 200 generations for the GA inversion (Figure 2). We estimate S-wave velocities 20 times with random seeds of initial populations for each CMPCC gather (black lines in Figure 2c) and define the average of them as the final S-wave velocity (blue line in Figure 2d). The detailed parameters in the GA inversion are summarized in Table 1.

Figures 2 and 3 demonstrate the effectiveness of this multimode analysis without mode identification because observed phase velocities are consistent with theoretical ones for the mode that has the strongest amplitude. In the case of a 70-m ice thickness (Figure 2), the amplitude of the first higher mode is smaller than those of the dominant modes (i.e., fundamental and second higher modes) in the entire frequency range used in this study $(5-30 \mathrm{~Hz})$. This may cause mode misidentification when we read the mode of observed phase velocities for frequencies higher than $17 \mathrm{~Hz}$. Therefore, the multimode analysis without mode identification is effective. Note that although the relative maxima of the observed phase velocity for frequencies near the mode transition zone can be readable, we only use the theoretical phase velocities of the absolute maximum for each frequency and neglect the phase velocities of the relative maxima because of the simplicity of an inversion algorithm. A possible improvement of the multimode inversion performed in this study is to incorporate the phase velocities of several relative maxima into the inversion algorithm.

The simulation studies indicate that the S-wave velocity can be estimated accurately using GA inversion when the ice is relatively thin (less than $70 \mathrm{~m}$ in Figure 2); these estimated velocities are largely consistent with the true velocity models (Figure 2d). However, the $\mathrm{S}$-wave velocity beneath thick glacial ice $(150 \mathrm{~m}$ in Figure 2$)$ is difficult to estimate, although the rms error is relatively small. The ice thickness is known from GPR studies, so we can use it in the inversion. When this information is used to fix the thickness of the shallowest ice layer ( $150 \mathrm{~m}$ in this case), the $\mathrm{S}$-wave velocity of
Figure 2. (a) Dispersion curves derived from the simulated data at the various ice thicknesses shown in Figure 1c (red dots) and from one of the estimated phase velocities of 20 trials (blue dots). Dashed lines indicate the amplitude response of each mode. (b) The rms error in the GA inversion. We estimate the velocity models 20 times with different random seeds for each CMPCC gather (thin black lines). The blue line indicates the average rms value. (c) Twenty results from S-wave velocity inversion (thin black lines). The light blue line indicates the reference velocity model used for the inversion. The red line indicates the true velocity model. (d) Final S-wave velocity profile (blue line) estimated by averaging the 20 results displayed in (c). The green line indicates the standard deviation (SD) for each depth.

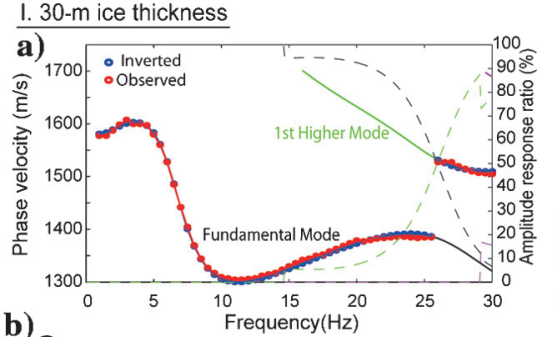

b)
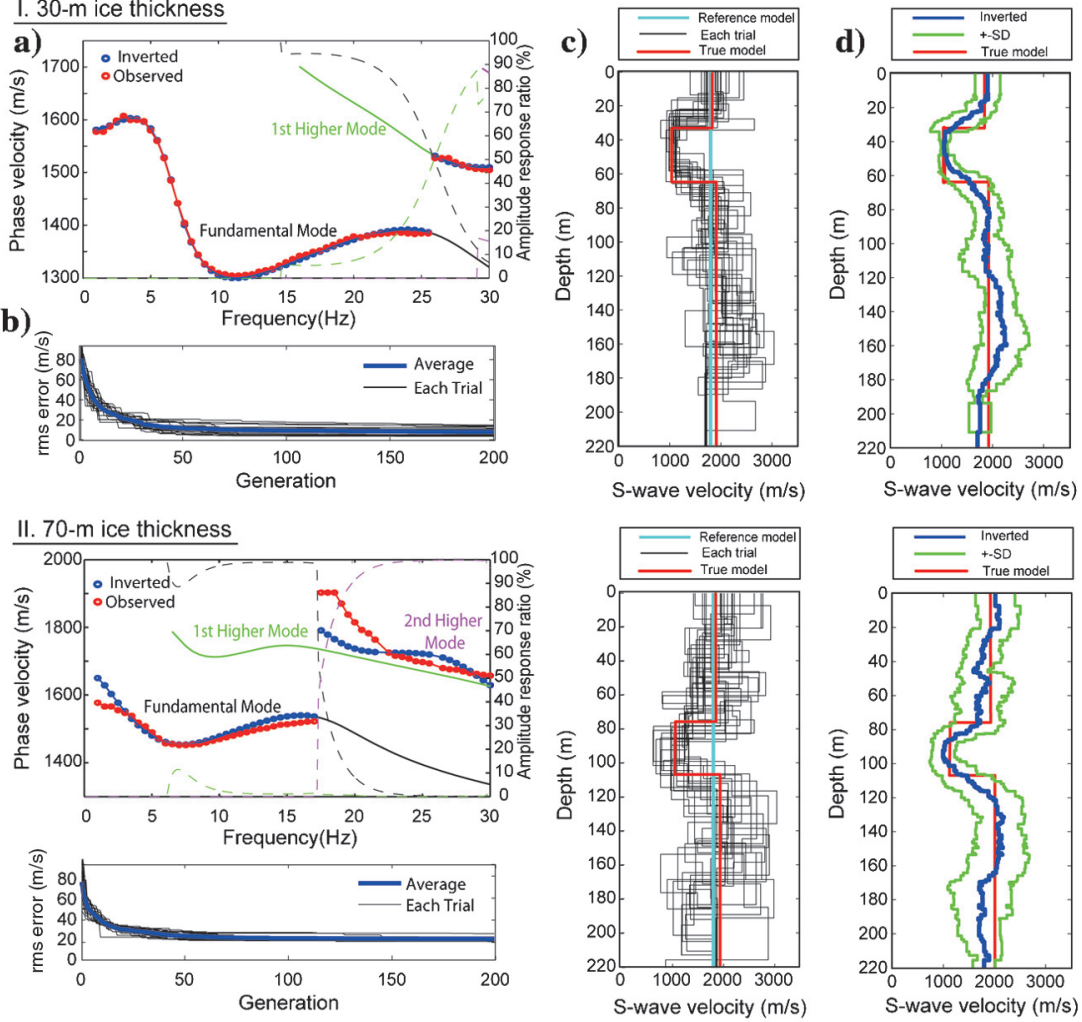

III. 150-m ice thickness
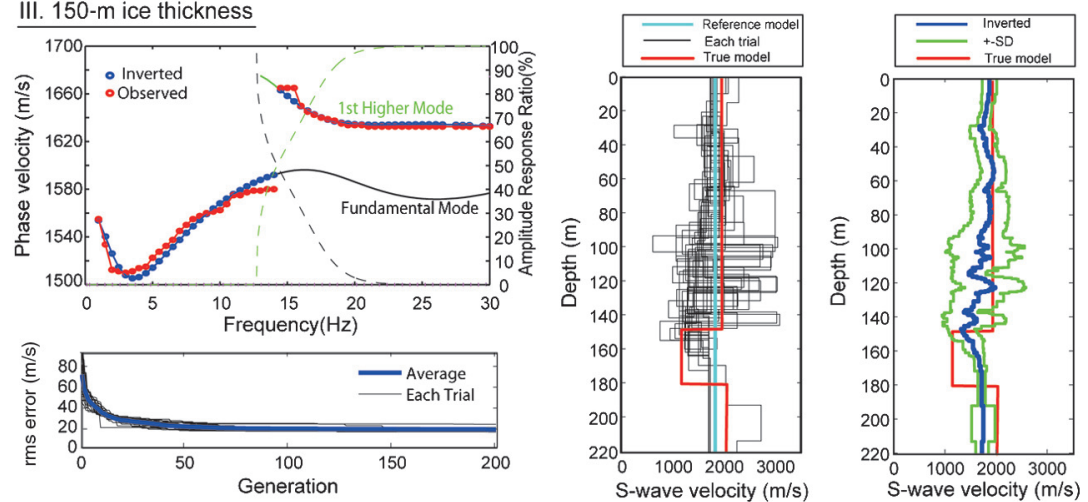
the deep subglacial sediment can be estimated accurately (Figure 3). Ice-thickness data are therefore important in surface-wave analysis of deep subglacial sediments. This simulation study demonstrates that the $\mathrm{S}$-wave velocity can be estimated for deep subglacial sediments if we acquire GPR data along the seismic survey line and use information about ice thickness in the inversion.

\section{SEISMIC DATA}

In 2009, the University of Bergen and Statoil, in conjunction with the University Center on Svalbard (UNIS) and Bergen Oilfield Services (BOS), conducted a 2D seismic-profiling campaign on glaciers at Nathorst Land in the Norwegian Arctic, located in south-central Spitsbergen and facing the Van Mijen fjord to the north and the Van Keulen fjord to the south (Johannessen et al., 2011; Johansen et al., 2011; Figure 4). In the study area at Nathorst Land, the glaciers are up to a few hundred meters thick. At the terminal margins of some glaciers, the appearance of meltwater ponds reveals that the temperature beneath the glaciers is above freezing, although generally the whole area of Spitsbergen is covered by permafrost. As the pressure increases toward the base of the glacier, the melting point of water decreases, and the ice melts. In this study, we use seismic data of line $1 \mathrm{~A}$ for the surface-wave analysis (green line in Figure 4). These multichannel seismic data were originally acquired for reflection analysis to resolve structures of deep subglacial sediments (e.g., Johansen et al., 2011) using the CMP technique. As such, the multichannel data are well suited for CMPCC analysis of surface waves.

The seismic data were acquired using a belted vehicle towing a 1500 -m-long snow streamer consisting of 60 geophone groups with a group distance of $25 \mathrm{~m}$ (Johansen et al., 2011). Although geophone grouping is usually used to filter out ground roll (surface waves), the surface waves we focus on in this study (frequency range $\sim 5-35 \mathrm{~Hz}$ ) are not severely affected by the grouping because of the high $\mathrm{S}$-wave velocity at the glacier surface $\left(V_{\mathrm{S}}=1839 \mathrm{~m} / \mathrm{s}\right)$. Each geophone group was equipped with eight equispaced $14-\mathrm{Hz}$ gimballed vertical geophones. The dispersion images computed from the CMPCC gathers show that reliable results could be obtained for frequencies down to about $5 \mathrm{~Hz}$.

The length of the survey line we use in this study is $7400 \mathrm{~m}$. The distance between shots was $50 \mathrm{~m}$, and each shot was made by a simultaneous ignition of two 50-m-long parallel lines of detonating cord deployed in the inline direction. The ignition point was at the front end of the line source, with a near offset of $125 \mathrm{~m}$. Some advantages of using detonating cord are that it is flexible and easy to handle under very low temperatures, fast to deploy, and, when used

$150-\mathrm{m}$ ice thickness (Fixed ice thickness in inversion)

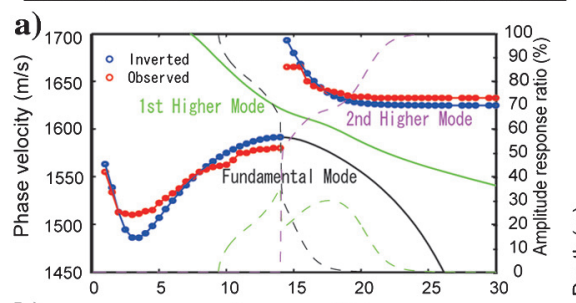

b)
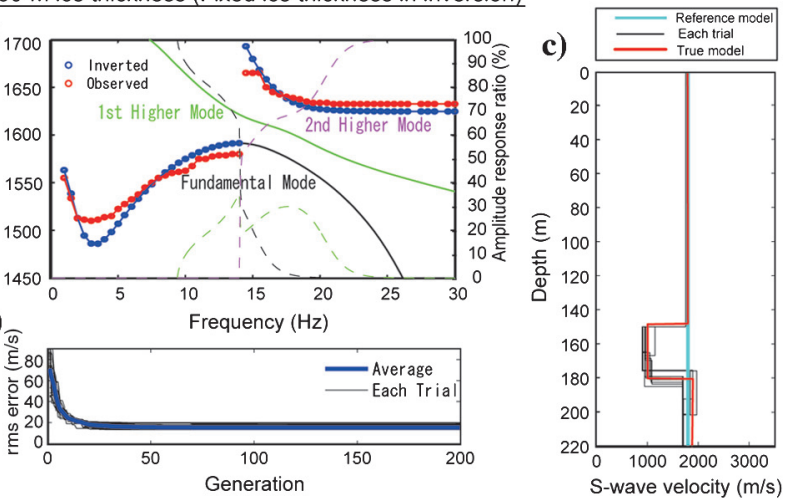

as a line source, gives favorable source directivity, with the main amplitude lobe pointing down and backward (Figure 5a). The source directivity of the line source causes the extent of spatial aliasing of high-frequency surface waves to be considerably less than that of a point source (Figure 5b, 5c, and 5d). This enables us to separate the P-waves from the $\mathrm{S}$ - and surface waves by $f-k$ filtering. The acquisition design is set to a temporal sampling rate of $2 \mathrm{~ms}$ and a recording time of $4 \mathrm{~s}$.

From the recorded shot gathers, we calculate $74 \mathrm{CMPCC}$ gathers with a 100-m horizontal interval. The surface waves are clearly identified on all CMPCC gathers. The prominent surface waves indicated in the CMPCC gathers (Figure 6a) are Rayleigh waves because vertical geophones were used. The slope and extent of the surface-wave pattern in the CMPCC gather are clearly seen to vary, mainly associated with the thickness of the glacier (Figure 6). We further identify airwaves on the CMPCC gather (Figure 6a).

\section{RESULTS AND DISCUSSION}

\section{Dispersion curves}

Dispersion images are calculated from all CMPCC gathers (Figure 6b) after applying a bandpass filter $(1-50 \mathrm{~Hz})$. The

Table 1. Parameters used in the GA inversion; $\gamma$ is the average coefficient of variation (Yamanaka and Ishida, 1996).

Parameters in GA inversion

Value

Generation

200

Population size

100

Crossover probability

Dynamic mutation probability

$\gamma \geq 0.1$

0.01

$0.04<\gamma<0.1$

0.05

$\gamma \leq 0.04$

0.1

Trial

Number of bit 6

Type of string

Decimal

Search range of $V_{\mathrm{S}}$ and thickness reference model

Figure 3. (a) Dispersion curves derived from the simulated data for an ice thickness of $150 \mathrm{~m}$ (red dots) and from one of the estimated phase velocities of 20 trials (blue dots). In the GA inversion, the ice thickness (first layer) is fixed. Dashed lines indicate the amplitude response of each mode. (b) The rms error in the GA inversion. We estimated the velocity models 20 times for each CMPCC gather (thin black lines). The blue line indicates the average rms value. (c) Twenty results from S-wave velocity inversion (thin black lines). The light blue line indicates the reference velocity model used for the inversion. The red line indicates the true model. (d) Final S-wave velocity profile (blue line) estimated by stacking the 20 results displayed in (c). The green line indicates the standard deviation (SD) for each depth. 


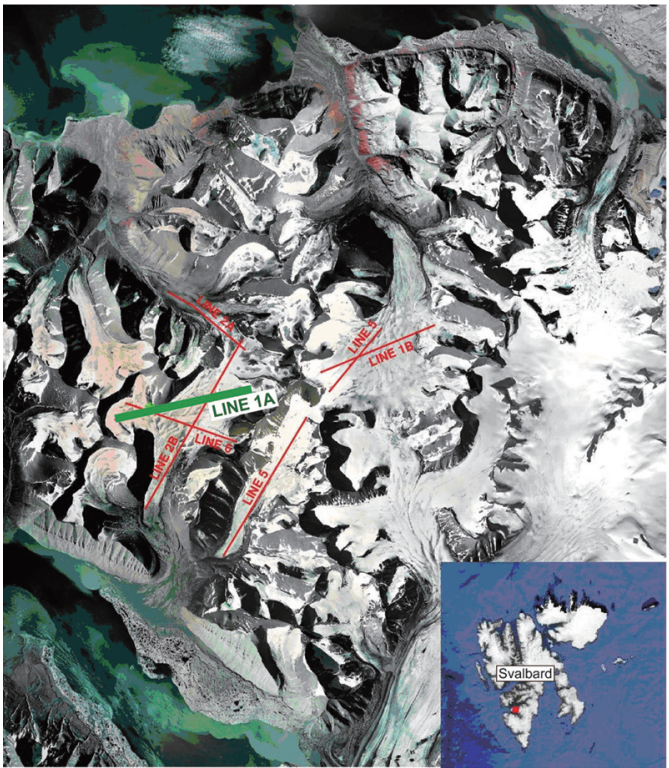

Figure 4. Survey area in the Norwegian Arctic, located in southcentral Spitsbergen (Johansen et al., 2011). The green line indicates the seismic survey profile used in this study. All seismic lines are located on glaciers. dispersion images show constant phase velocity in the highfrequency range (above $20 \mathrm{~Hz}$ ) due to constant velocity within the glacier ice. At the profile distance of $3000 \mathrm{~m}$ where the ice sheet is at its thickest, the phase velocity is approximately $1800 \mathrm{~m} / \mathrm{s}$ over a wide frequency range $(9-30 \mathrm{~Hz}$; Figure $6 \mathrm{~b})$. Because the higher modes are observed in almost all dispersion curves and because the simulation study shows an importance of higher modes, we decide to use the multimode inversion from the simulation study.

We observe transitions of the dominant modes on the dispersion curves (Figure 6). When the phase velocities of the dominant mode of all CMPCC gathers are displayed (Figure 7a), the mode transition is observed continuously for horizontal (survey line) direction (white dots in Figure 7a). The higher modes could be induced by a low-velocity layer beneath the glacier or at the interface between glacier ice and sediment. From the simulation study, the transition of dominant modes observed on the dispersion curve seems to be related to ice thickness when the velocity structure beneath the glacier is similar. Furthermore, as an approximate inversion, 1.1 times phase velocities versus wavelength divided by a factor $\alpha$ (where $\alpha \sim 2-4)$ is transformed as $\mathrm{S}$-wave velocity versus depth (Figure 7b; e.g., Heisey et al., 1982; Abbiss, 1983; Socco et al., 2010). Therefore, we can roughly estimate the geometry of the subglacial sediment surface (location of low-velocity layer; Figure 7c)

a)
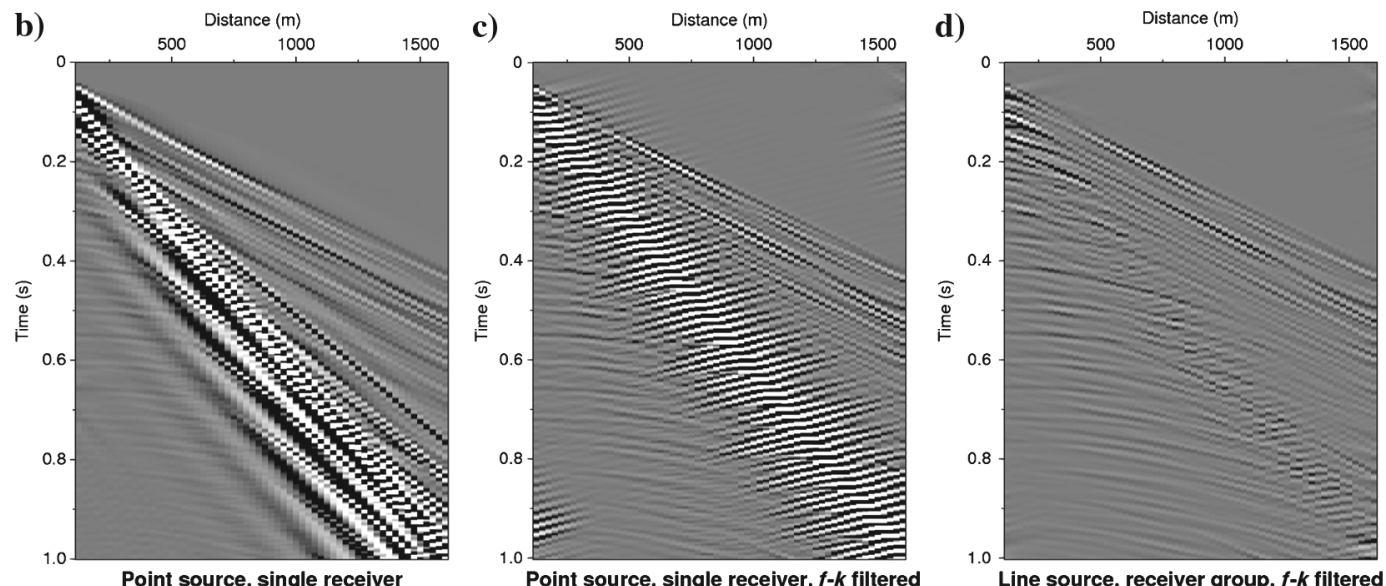

Figure 5. (a) Simulated source directivity from a line source of 50-m length and with a detonation velocity of $7.0 \mathrm{~km} / \mathrm{s}$ on top of a half-space with a P-wave velocity of $4.0 \mathrm{~km} / \mathrm{s}$. The amplitudes are computed for plane waves with different incidence angles and frequencies. (b) Shot gather of point source computed with the reflectivity method for a model with a 100-m-thick glacier overlying high-velocity sedimentary rocks (P-wave velocities of 4.0-5.0 km/s). (c) The $S$-waves and surface waves from the gather in (b) are partly removed using an $f$ - $k$ filter. The strong backward-dipping events are due to spatial aliasing. (d) The responses of the line source and the receiver groups are included in the modeling (similar to the acquisition setup), resulting in an $f$ - $k$-filtered gather with strongly reduced spatial aliasing. 
from the transition of dominant modes on the dispersion images (Figure $7 \mathrm{a}$ and $7 \mathrm{~b}$ ).

\section{Estimated S-wave velocity distribution with fixed thickness of the glacier}

After performing the GA inversion, the theoretical dispersion curve calculated from the inverted S-wave velocity model is somewhat consistent with the observed curve (Figure 8a). In the inversion, we fix the thickness of the shallowest (ice) layer obtained from GPR data (Johansen et al., 2011; Figure 7c) because the simulation study (Figure 3) demonstrates that including the known ice thickness will improve the inversion results. The reference model used in the GA inversion contains a zone of a slightly lower velocity beneath the ice (light blue line in Figure 8c) because this reference velocity model constructed by trial-and-error forward modeling can roughly explain the observed dispersion curve. Other parameters used in the GA inversions are the same as the simulation study (Table 1). By averaging the 20 results obtained from the GA inversions at each CMPCC point (thin black lines in Figure 8c), smoothed $\mathrm{S}$-wave velocity structures are obtained (blue line in Figure 8d). We further estimate the S-wave velocity models from
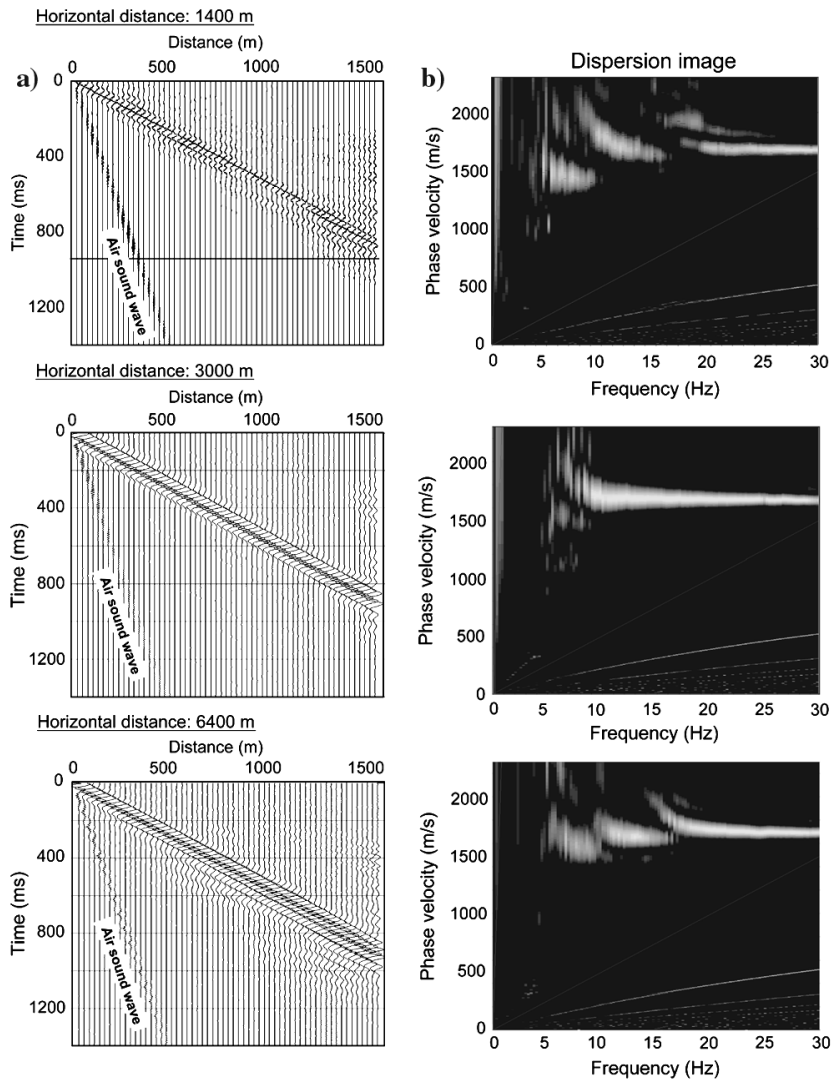

Figure 6. (a) CMPCC gathers and (b) their dispersion images at horizontal distances of 1400, 3000, and $6400 \mathrm{~m}$ (blue arrows in Figure 7). Because the thickest ice $(\sim 190 \mathrm{~m})$ occurs at a horizontal distance of $3000 \mathrm{~m}$, the phase velocity is constant for a wide frequency range. The artifacts in the lower-right corner of the images are due to aliasing, which may occur when the receiver interval is long compared to the wavelength. all of the CMPCC gathers and obtain the S-wave velocity distribution along the seismic line (Figure 9a). Because the subglacial sediment layers are steeply dipping, we estimate S-wave velocity at each CMPCC point independently without applying horizontal regularization in inversion.

From the obtained velocity distribution (Figure 9a), we estimate the S-wave velocity within the glacier ice as approximately $1800 \mathrm{~m} / \mathrm{s}$. However, the S-wave velocity in the ice varies laterally, and at places with thin ice ( 2000 and $5000 \mathrm{~m}$ horizontal distance in Figure 9a), it is significantly higher than the expected velocity $(\sim 1800 \mathrm{~m} / \mathrm{s})$. Its standard deviation (Figure $9 \mathrm{~b})$ is also larger here than at the surrounding places. This lateral variation in velocity within the glacier could be erroneously generated by sediment surface roughness because large lateral velocity variation may not have been completely resolved, although we use the CMPCC method to increase lateral resolution. Furthermore, the dispersion curve calculated from the inverted velocity structure is not consistent with the observed dispersion curve in the lowfrequency range (Figure $8 \mathrm{a}$ ). The rms error has a different value for each GA inversion (Figure 8b), and the estimated $20 \mathrm{~S}$-wave velocities have significant variations for each inversion (Figures 8c, 8d, and 9b). It is therefore difficult to find the global minimum in the GA inversion by only constraining the thickness of ice.

\section{Estimated S-wave velocity distribution with fixed thickness, velocity, and density of glacier ice}

To improve the results of the GA inversion, we use fixed values for the $\mathrm{S}$-wave velocity $\left(V_{\mathrm{S}}=1839 \mathrm{~m} / \mathrm{s}\right), \quad \mathrm{P}$-wave velocity $\left(V_{\mathrm{P}}=3466 \mathrm{~m} / \mathrm{s}\right)$, and density of the glacier ice (first layer), in addition to the thickness. Using these known fixed values for the glacier, we can estimate more continuous $\mathrm{S}$-wave velocity structures for the subglacial sediments (Figures 10 and 11a), and the rms error (Figures $10 \mathrm{~b}$ and $11 \mathrm{c}$ ) is much smaller than previous cases (Figures $8 \mathrm{~b}$ and 9c). Furthermore, because the standard deviation (Figures 10d and 11b) is much smaller than for the previous case (Figures $8 \mathrm{~d}$ and $9 \mathrm{~b}$ ), we obtain much more stable results by fixing $\mathrm{S}$ - and $\mathrm{P}$-wave velocities and density for glacier ice in the inversion.

The S-wave velocity within most of the subglacial sediment (Figure 11) is approximately $1500 \mathrm{~m} / \mathrm{s}$, which is lower than the velocity of pure ice $(1800 \mathrm{~m} / \mathrm{s})$. Significantly lower velocity $(\sim 1300 \mathrm{~m} / \mathrm{s})$ is estimated at the ice-sediment interface beneath thick ice (e.g., 3300 and 6500-m horizontal distance in Figure 11a). This velocity is so low that it could be interpreted as an unconsolidated sediment (moraine). However, it seems unlikely that such a thick layer of moraine material should exist below the glacier as it would normally be removed by the moving ice. Therefore, our interpretation is that the low velocities are due to deep glacial erosion and (partly) unfrozen pore water in the sedimentary rocks.

At the topological high (or shallow ice-sediment interface) at approximately $5000 \mathrm{~m}$ horizontal distance (ice thickness less than $50 \mathrm{~m}$; Figure 11a), the S-wave velocity is similar to the pure ice value $(\sim 1800 \mathrm{~m} / \mathrm{s})$, suggesting that subglacial sediment at the shallower part of the topological high is more frozen than the sediments at the deeper ice-sediment interface. Furthermore, high S-wave velocities are observed several places within the subglacial sediment ( $\sim 2800 \mathrm{~m} / \mathrm{s})$. Because the S-wave velocity changes significantly at a critical ratio of porewater to ice and with the degree of saturation 
EN24
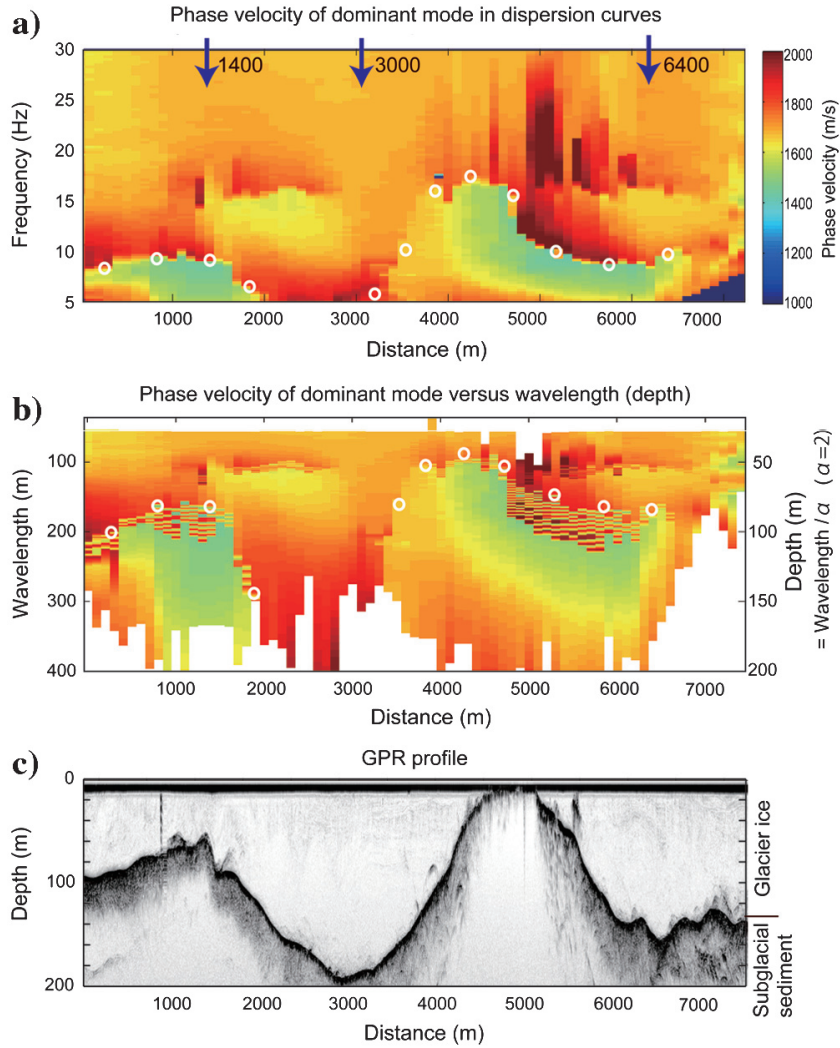

Figure 7. (a) Phase velocity of the dominant mode for each frequency, derived from all CMPCC gathers. Vertical and horizontal axes indicate frequency and distance for the survey line direction, respectively. White dots indicate the transition of dominant modes. The blue arrows indicate the locations of dispersion curves displayed in Figure 6. (b) Phase velocity of the dominant mode versus wavelength. The vertical axis can be converted to depth when we assume $\alpha$ for the conversion (depth $=$ wavelength $/ \alpha$ ). In this profile, we use $\alpha=2$ for the conversion. (c) Ice thickness estimated from GPR data. Because the line was acquired from east to west, distances are measured from the east end of the line.
Tsuji et al.
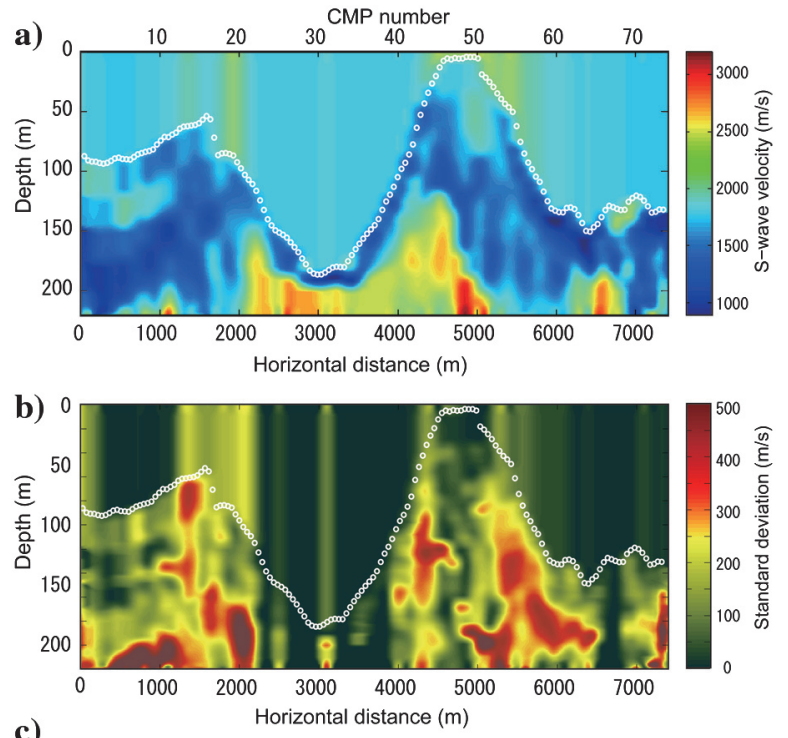

c)

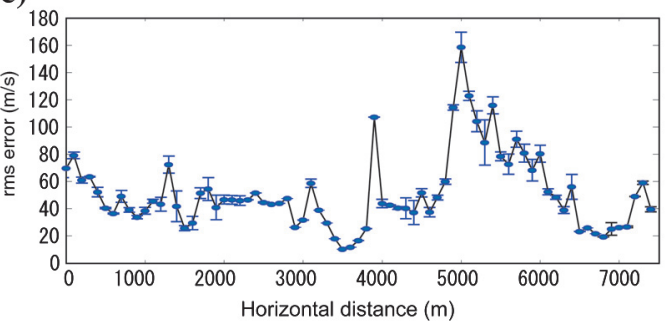

Figure 9. (a) Estimated S-wave velocity distribution. Here we have only fixed the thickness of ice (first layer). White dots indicate the ice-sediment interface. (b) The 2D standard deviation distribution of the S-wave velocity section (a). This value corresponds to the green line in Figure 8d. (c) Average rms error with its deviation from 20 trials at each CMPCC location.
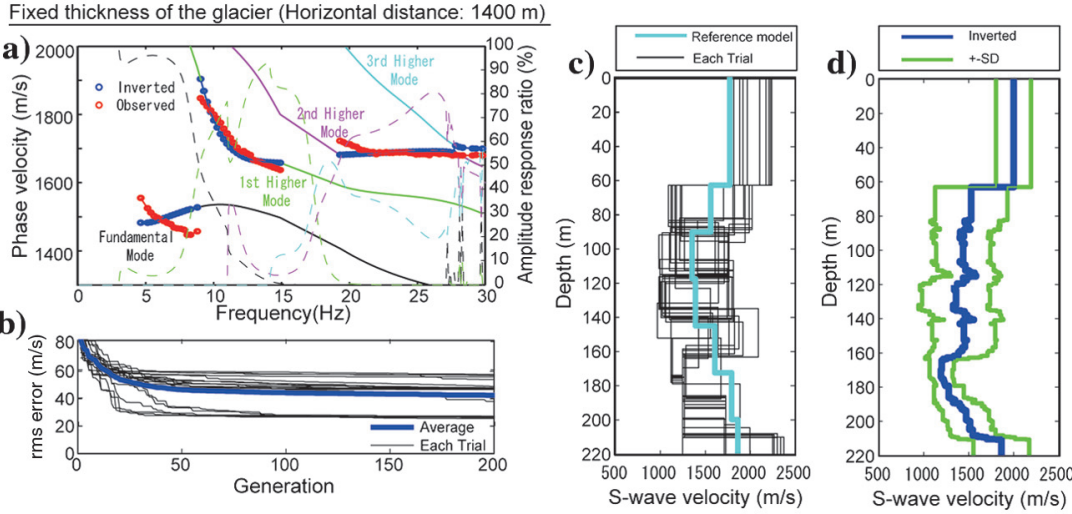

Figure 8. (a) Example of dispersion curves derived from the field data (red dots) and from GA inversion (blue dots) at 1400-m horizontal distance. Here we have only fixed the thickness of the first layer (ice thickness derived from GPR data). Dashed lines indicate the amplitude response of each mode. (b) The rms error in GA inversion. We estimate the velocity models 20 times for each CMPCC gather (thin black lines). The blue line indicates the average rms error. (c) Twenty results from S-wave velocity inversion (black thin lines). The light blue line indicates the reference velocity model used for the inversion. (d) Final S-wave velocity profile (blue line) estimated by stacking the 20 results displayed in (c). The green line indicates the standard deviation (SD) for each depth. 
Fixed thickness, velocity and density of the glacier (Horizontal distance: $1400 \mathrm{~m}$ )
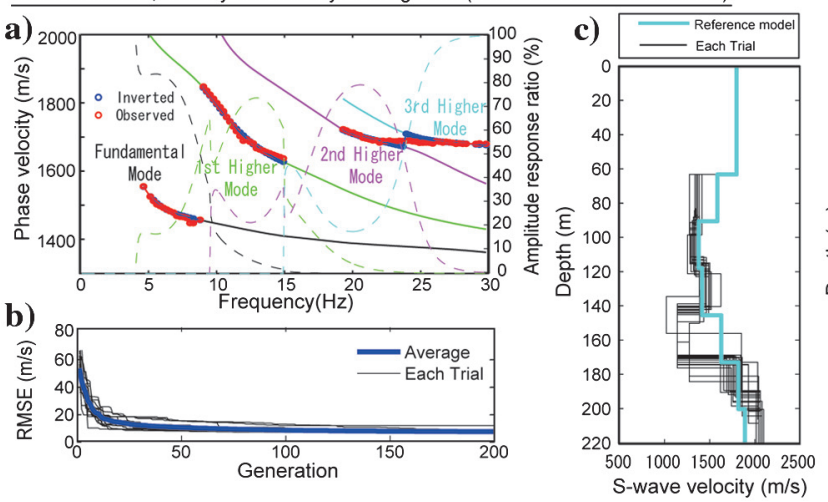

(Johansen et al., 2003), the variations in S-wave velocity within subglacial sediment can be explained by the degree of freezing as well as pore-space saturation (Zimmermann and King, 1986; Jacoby et al., 1996; Johansen et al., 2003).

\section{CONCLUSIONS}

Six main results were obtained in this study:

First, to reveal the S-wave velocity distribution in the subglacial sediment, we applied MASW to active-source multichannel seismic data originally acquired for reflection analysis along a glacier at Spitsbergen in the Norwegian Arctic.

Second, because higher modes were observed in the dispersion curves indicating potential lowvelocity layer under glacier ice, we used multimode analysis with a GA inversion to estimate S-wave velocity profiles. We employed the multimode inversion without mode identification to avoid mode misidentification for the extracted dispersion curve.

Third, because of significant lateral variation in the S-wave velocity associated with the steep slope of the subglacial sediment surface, CMPCC gathers were used for the surface-wave analysis to improve the lateral resolution of the long-receiver array data.

Fourth, by including ice thickness derived from GPR data and by
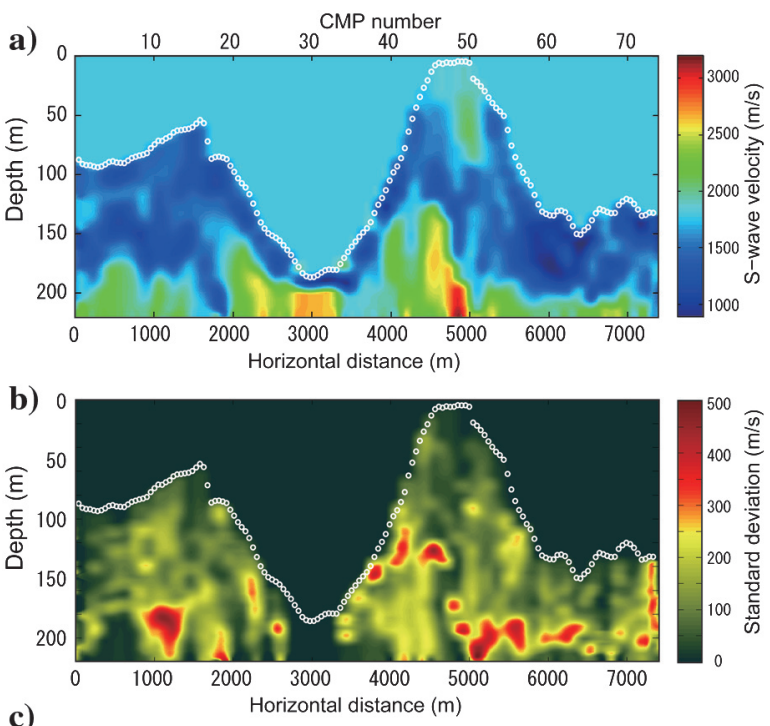
using constant $\mathrm{P}$ - and $\mathrm{S}$-wave velocities and density for glacial ice in surface-wave analysis, the S-wave velocity distribution of subglacial sediments was estimated accurately.

Fifth, the resolution of the glacier-sediment interface for GPR data is much higher than that obtained by surface wave analysis. However, due to the limited radar penetration within subglacial sediments, it is hard to resolve properties within the deeper subglacial sediments. Therefore, we integrated the ice thickness derived from GPR data in the surface-wave analysis and improved the resolution of the S-wave velocity.

Finally, the S-wave velocity distribution estimated in our study clearly indicated zones of lower velocities beneath the glaciers. The variation in S-wave velocity reflected change in the pore-space stiffness associated with partial or complete freezing of the pore fluid in the sediment.

\section{ACKNOWLEDGMENTS}

We are grateful to K. Hayashi (OYO Co. Ltd.) for helpful comments. We also thank C. Zeng, L. V. Socco, an anonymous referee, and Associate Editor J. Irving for helpful reviews of the manuscript. The seismic data were acquired by the University of Bergen and Statoil, in conjunction with the University Centre on Svalbard (UNIS) and Bergen Oilfield Services (BOS). This study was partially supported by the JSPS Excellent Young Researcher Overseas Visit Program (21-5336).

\section{APPENDIX A}

\section{INFLUENCE OF LAYER NUMBERS TO THE INVERTED RESULTS}

In this study, we use a seven-layer model for the inversion (Figures 2, 3, 8, and 10). However, the number of layers used in 
Tsuji et al.
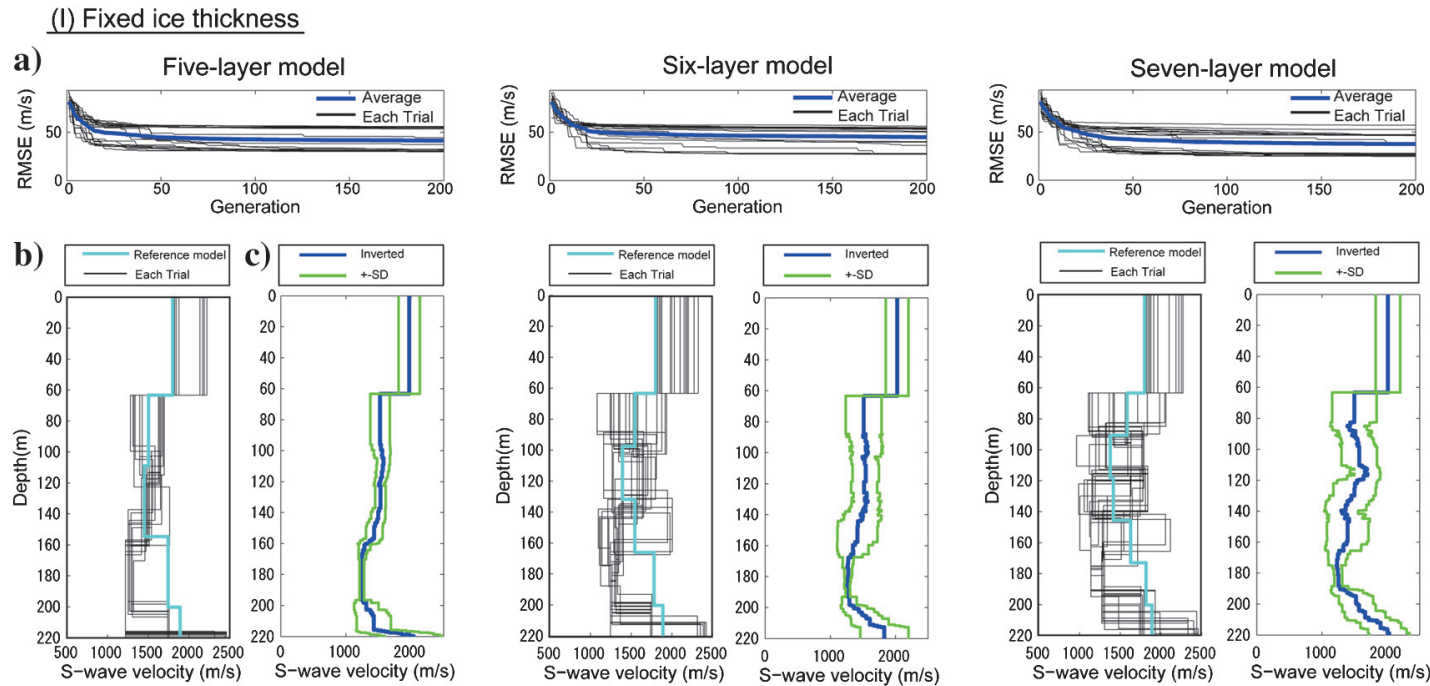

(II) Fixed thickness, velocity and density of glacier ice
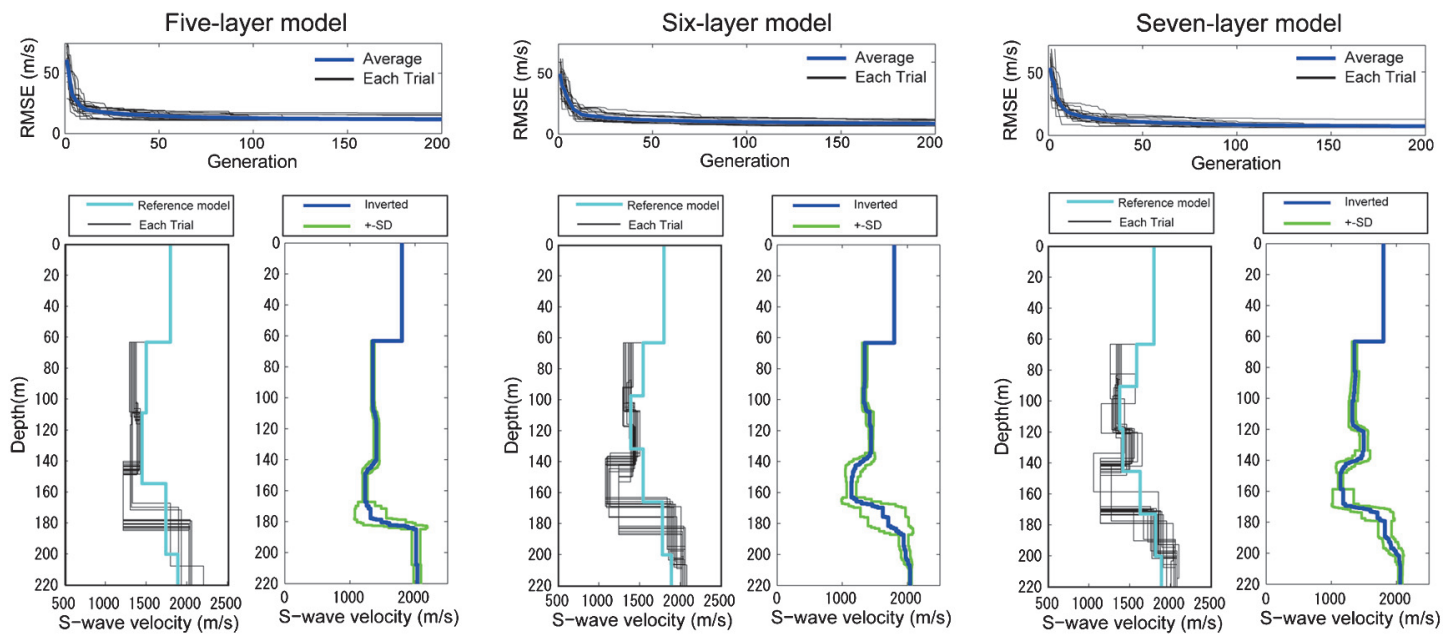

Figure A-1. Inversion results derived from five-layer, six-layer, and seven-layer models ( $\sim 1400 \mathrm{~m}$ horizontal distance). The results for (I) fixed ice thickness are shown in the upper part, and the results for (II) fixed ice thickness, P- and S-wave velocities and density of ice are shown in the lower part. The results of the seven-layer model are identical to Figures 8 and 10. (a) The rms error in GA inversion. (b) Twenty results from $\mathrm{S}$-wave velocity inversion (black thin lines). The light blue line indicates the reference velocity model used for inversion. (c) Final S-wave velocity profile (blue line). The green line indicates the standard deviation (SD) for each depth.

the inversion would influence the final results. There is a possibility that the inversion using seven layers (Figure 10) is overparameterized for the determination of velocity of deep layers. To evaluate the influence of number of layers on the final results, we estimate S-wave velocity using models with a reduced number of layers. Here we use five- and six-layer models in addition to the seven-layer model for the inversion and compared the results (Figure A-1).

Although the standard deviation of the seven-layer model is larger than that of the five-layer model in the case of (I) fixed ice thickness in Figure A-1, the standard deviation is similar for all three models in the case of (II) fixed ice thickness, P- and S-wave velocities, and density of glacier. Furthermore, the rms errors of all cases are similar. This observation demonstrates that reliable S-wave velocity can be estimated by using a seven-layer model. Because the models with a large number of layers generate results of higher resolution (e.g., deep subglacial sediment in Figure A-1), we use the seven-layer model in this study.

\section{REFERENCES}

Abbiss, C. P., 1983, Calculation of elasticities and settlements for longer periods of time and high strains from seismic measurements: Geotechnique, 33, 397-405, doi: 10.1680/geot.1983.33.4.397.

Bouchon, M., and K. Aki, 1977, Discrete wave-number representation of seismic-source wave fields: Bulletin of the Seismological Society of America, 67, 259-277.

Gucunski, N., and R. D. Woods, 1992, Numerical simulation of the SASW test: Soil Dynamics and Earthquake Engineering, 11, 213-227.

Harkrider, D. G., 1964, Surface waves in multilayered elastic media. Part I. Rayleigh and Love waves from buried sources in a multilayered elastic half-space: Bulletin of the Seismological Society of America, 54, 627-679.

Harkrider, D. G., 1970, Surface waves in multilayered elastic media. Part II. Higher mode spectra ratios from point sources in plane layered earth models: Bulletin of the Seismological Society of America, 60, 1937-1987. 
Hayashi, K., and H. Suzuki, 2004, CMP crosscorrelation analysis of multichannel surface-wave data: Exploration Geophysics, 35, 7-13, doi: 10 .1071/EG04007.

Heisey, J. S., K. H. Stokoe II, W. R. Hudson, and A. H. Meyer, 1982, Determination of in situ shear wave velocities from spectral analysis of surface waves: Research report, 25-2, Center for Transportation Research, University of Texas at Austin.

Jacoby, M., J. Dvorkin, and X. Liu, 1996, Elasticity of partially saturated frozen sand: Geophysics, 61, 288-293, doi: 10.1190/1.1443951.

Johannessen, E. P., T. Henningsen, N. E. Bakke, T. A. Johansen, B. O. Ruud, P. Riste, H. Elvebakk, M. Jochmann, G. Elvebakk, and M. S. Woldengen, 2011, Palaeogene clinoform succession on Svalbard expressed in outcrops, seismic data, logs and cores: First Break, 29, 35-44, doi: 10 $.3997 / 1365-2397.2011004$.

Johansen, T. A., P. Digranes, M. van Schaack, and I. Lønne, 2003, Seismic mapping and modeling of near-surface sediments in polar areas: Geophysics, 68, 566-573, doi: 10.1190/1.1567226.

Johansen, T. A., B. O. Ruud, N. E. Bakke, P. Riste, E. Johannessen, and T. Henningsen, 2011, Seismic profiling on Arctic glaciers: First Break, 29, 65-71.

Kennett, B. L. N., and N. J. Kerry, 1979, Seismic waves in a stratified halfspace: Geophysical Journal of the Royal Astronomical Society, 57, no. 3 , 557-583, doi: 10.1111/j.1365-246X.tb06779.x.

Kim, K. Y., J. Lee, M. H. Hong, Y. K. Jin, and H. Shon, 2010, Seismic and radar investigations of Fourcade Glacier on King George Island, Antarctica: Polar Research, 29, no. 3, 298-310, doi: 10.1111/j.1751-8369.2010 .00174.x.

Kitsunezaki, C., N. Goto, Y. Kobayashi, T. Ikawa, M. Horike, T. Saito, T. Kurota, K. Yamane, and K. Okuzumi, 1990, Estimation of P- and S-wave velocities in deep soil deposits for evaluating ground vibrations in earthquake (in Japanese): Sizen-saigai-kagaku, 9-3, 1-17.

Lin, C.-P., C.-C. Chang, and T.-S. Chang, 2004, The use of MASW method in the assessment of soil liquefaction potential: Soil Dynamics and Earthquake Engineering, 24, 689-698, doi: 10.1016/j.soildyn.2004 .06 .012 .

Lu, L., and B. Zhang, 2006, Inversion of Rayleigh waves using a genetic algorithm in the presence of a low-velocity layer: Acoustical Physics, 52, 701-712, doi: 10.1134/S106377100606011X.

Ludwig, W. J., J. E. Nafe, and C. L. Drake, 1970, Seismic refraction, in A. E. Maxwell, ed., The Sea: Ideas and observations on progress in the study of the seas, 4: Wiley-Interscience, 53-84.

McMechan, G. A., and M. J. Yedlin, 1981, Analysis of dispersive waves by wave field transformation: Geophysics, 46, 869-874, doi: 10.1190/ 1.1441225 .

Nazarian, S., K. H. Stokeo, and W. R. Hudson, 1983, Use of spectral analysis of surface waves method for determination of moduli and thickness of pavement system: Transportation Research Board, 930, $38-45$.
O'Neill, A., and T. Matsuoka, 2005, Dominant higher surface-wave modes and possible inversion pitfalls: Journal of Environmental and Engineering Geophysics, 10, no. 2, 185-201, doi: 10.2113/JEEG10.2.185.

Park, C. B., R. D. Miller, and J. Xia, 1998, Imaging dispersion curves of surface waves on multi-channel record: 68th Annual International Meeting, SEG, Expanded Abstracts, 1377-1380.

Park, C. B., R. D. Miller, and J. Xia, 1999a, Multimodal analysis of high frequency surface waves: Proceedings of the Symposium on the Application of Geophysics to Engineering and Environmental Problems (SAGEEP), 115-121.

Park, C. B., R. D. Miller, and J. Xia, 1999b, Multichannel analysis of surface waves: Geophysics, 64, 800-808, doi: 10.1190/1.1444590.

Saito, M., and H. Kabasawa, 1993, Computation of reflectivity and surface wave dispersion curves for layered media; 2 . Rayleigh wave calculations (in Japanese): Butsuri-tansa, 46, 283-298.

Schwab, F., and L. Knopoff, 1972, Fast surface wave and free mode computations, in B.A. Bolt, ed., Methods in computational physics: Academic Press, 11, 87-180.

Socco, L. V., S. Foti, and D. Boiero, 2010, Surface-wave analysis for building near-surface velocity models - Established approaches and new perspectives: Geophysics, 75, no. 5, A83-A102, doi: 10.1190/1.3479491.

Tokimatsu, K., S. Tamura, and H. Kojima, 1992, Effects of multiple modes on Rayleigh wave dispersion characteristics: Journal of Geotechnical Engineering, 118, 1529-1543, doi: 10.1061/(ASCE)0733-9410(1992)118: 10(1529).

Watson, T. H., 1970, A note on fast computation of Rayleigh wave dispersion in multilayered elastic half-space: Bulletin of the Seismological Society of America, 60, 161-166.

Woodward, J., T. Murray, R. A. Clark, and G. W. Stuart, 2003, Glacier surge mechanisms inferred from ground-penetrating radar: Kongsvegen, Svalbard: Journal of Glaciology, 49, no. 167, 473-480, doi: 10.3189/ 172756503781830458

Xia, J., R. D. Miller, and C. B. Park, 1999, Estimation of near-surface shearwave velocity by inversion of Rayleigh waves: Geophysics, 64, 691-700, doi: 10.1190/1.1444578.

Yamanaka, H., and H. Ishida, 1996, Application of genetic algorithms to an inversion of surface-wave dispersion data: Bulletin of the Seismological Society of America, 86, 436-444.

Yao, H., C. Beghein, and R. D. Van Der Hilst, 2008, Surface wave array tomography in SE Tibet from ambient seismic noise and two-station analysis - II. Crustal and upper-mantle structure: Geophysical Journal International, 173, 205-219, doi: 10.1111/gji.2008.173.issue-1.

Zhang, S. X., and L. S. Chan, 2003, Possible effects of misidentified mode number on Rayleigh wave inversion: Journal of Applied Geophysics, $\mathbf{5 3}$ no. 1, 17-29, doi: 10.1016/S0926-9851(03)00014-4.

Zimmermann, R. W., and M. King, 1986, The effect of the extent of freezing on seismic velocities in unconsolidated permafrost: Geophysics, 51, 1285-1290, doi: 10.1190/1.1442181. 